\title{
Cavitating lung infarction after bland pulmonary thromboembolism in patients with the adult respiratory distress syndrome
}

\author{
SUSAN REDLINE, JOSEPH F TOMASHEFSKI jun, MURRAY D ALTOSE \\ From the Department of Medicine, Pulmonary Division, and Department of Pathology, Cleveland \\ Metropolitan General Hospital and Case Western Reserve University, Cleveland, Ohio, USA
}

\begin{abstract}
During one year five patients were observed with the adult respiratory distress syndrome who were found at necropsy to have cavitated lung infarcts following bland (non-infected) pulmonary thromboembolism. There were three instances of bronchopleural fistula and in one person a tension pneumothorax was the immediate cause of death. Four of the five patients had severe lung infections. In all patients airway pressure was raised as a result of positive pressure mechanical ventilation. It is postulated that diffuse microvascular injury, bacterial pneumonia, and high airway pressures may be important factors predisposing patients with adult respiratory distress syndrome to develop lung necrosis, cavitation, and bronchopleural fistula after bland pulmonary thromboembolism. This complication may occur more frequently than has been previously recognised.
\end{abstract}

The histological changes in the lung that develop after bland (non-infected) pulmonary thromboembolism usually consist of intra-alveolar haemorrhage and interstitial oedema without destruction of lung parenchyma. ${ }^{1}$ About $15 \%$ of pulmonary thromboemboli will produce lung infarction. ${ }^{2}$ Extensive tissue necrosis with cavitation and the development of bronchopleural fistula has, however, been reported to occur only rarely. During one year, among 232 necropsies, we observed six patients with cavitated pulmonary infarcts secondary to bland thromboembolism with three instances of bronchopleural fistula. Of these patients, five had the adult respiratory distress syndrome. This report describes the clinical and pathological aspects of these five cases and suggests that coexisting lung injury due to adult respiratory distress syndrome, pulmonary infection, and high positive airway pressures produced by mechanical ventilation may be important in the development of cavitation and bronchopleural fistula after pulmonary infarction.

Address for reprint requests: Dr Murray D Altose, Cleveland Metropolitan General Hospital, 3395 Scranton Road, Cleveland, Ohio 44109, USA.

Accepted I July 1985

\section{Case reports}

CASE 1

A 32 year old man was admitted to hospital in a comatose state after intravenous self administration of ethchlorvynol (Placidyl). The blood pressure was $90 / 50 \mathrm{~mm} \mathrm{Hg}$, his temperature $39^{\circ} \mathrm{C}$, and his respiratory rate was $28 / \mathrm{min}$. A chest radiograph showed diffuse bilateral patchy shadowing. Because of rapidly progressive hypoxaemia, he underwent endotracheal intubation and mechanical ventilation. His hospital course was complicated by granulocytopenia and disseminated intravascular coagulation. On the third hospital day blood cultures yielded Escherichia coli and microbiological examination of sputum showed abundant mixed Gram negative bacillary organisms. Positive end-expiratory pressures (PEEP) of $5-18 \mathrm{~cm}$ $\mathrm{H}_{2} \mathrm{O}$ and an inspired oxygen concentration of $50 \%$ $\left(\mathrm{FiO}_{2} \mathrm{0.50}\right)$ were required to achieve an arterial oxygen tension $\left(\mathrm{PaO}_{2}\right)$ of $65 \mathrm{~mm} \mathrm{Hg}(8.6 \mathrm{kPa})$. On the sixth hospital day a right pneumothorax developed and a chest tube was placed in the pleural space. Two days later a flow directed pulmonary artery catheter was inserted via the right subclavicular vein. On the 10th hospital day the systolic blood pressure dropped to 60 $\mathrm{mm} \mathrm{Hg}$, and arterial blood analysis showed a $\mathrm{pH}$ of 7.21 , a carbon dioxide tension $\left(\mathrm{PaCO}_{2}\right)$ of $64 \mathrm{~mm} \mathrm{Hg}$ $(8.5 \mathrm{kPa})$, and $\mathrm{a} \mathrm{PaO}_{2}$ of $35 \mathrm{~mm} \mathrm{Hg}(4.7 \mathrm{kPa})$. The 


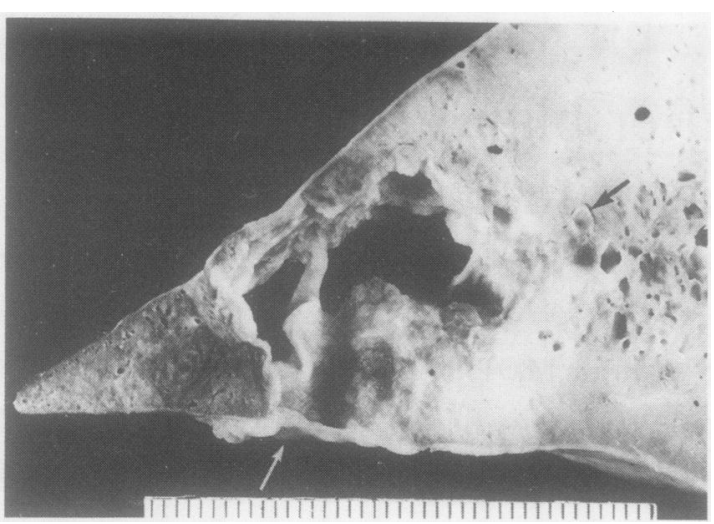

Fig 1 Patient 1: This irregular cavity has perforated the pleura inferiorly (light arrow). Adjacent to the defect, in the costophrenic angle, there is recent haemorrhage. A thromboembolus occludes a subsegmental artery proximal to the cavity (dark arrow). (Scale in $\mathrm{mm}$.)

peak airway pressure was $60 \mathrm{~cm} \mathrm{H}_{2} \mathrm{O}$. A chest radiograph showed a large left tension pneumothorax. Shortly afterwards he suffered a cardiopulmonary arrest and died.

\section{Pathological findings}

At necropsy the lungs were heavy and diffusely consolidated. The left lung had retracted toward the mediastinum owing to the recent pneumothorax. In the inferior portion of the left lateral basal segment there was an area of haemorrhage and necrosis with a $2 \times 1 \mathrm{~cm}$ central abscess that communicated with the pleural space through necrotic visceral pleura (fig 1). An organising thromboembolus was present in a subsegmental artery at the apex of the lesion, while several bland microemboli were scattered throughout both lungs. The parenchymal consolidation represented organising diffuse alveolar damage with multiple foci of acute pneumonia. Postmortem lung cultures grew Pseudomonas aeruginosa. Other related findings included a thrombus in the superior vena cava.

\section{CASE 2}

A 42 year old woman had a four month history of dermatomyositis treated with high doses of corticosteroids. For two months before admission she had experienced recurrent fever and shortness of breath. On admission her temperature was $39^{\circ} \mathrm{C}$ and her respiratory rate was 28 per minute. A chest radiograph showed diffuse bilateral reticulonodular infiltrates and a large pleural based area of consolidation in the inferolateral left lung field. Bronchoscopy was performed and microscopical examination of a transbronchial biopsy specimen from the left lower lobe showed features of necrotic lung. Microscopic examination of stained specimens of bronchial washings showed acid fast bacilli. Cultures $\overrightarrow{0}$ of lung tissue yielded Serratia marcesans and later Mycobacterium tuberculosis. Broad spectrum antimicrobial treatment was instituted (tobramycin, ticarcillin, isoniazid, ethambutol, rifampicin). Gas exchange progressively deteriorated and mechanical ventilation with an $\mathrm{FiO}_{2}$ of 0.70 and a PEEP of $5 \mathrm{~cm}$ $\mathrm{H}_{2} \mathrm{O}$ was instituted. The $\mathrm{PaO}_{2}$ was $70 \mathrm{~mm} \mathrm{Hg}(9.3$ $\mathrm{kPa})$ and $\mathrm{PaCO}_{2} 36 \mathrm{~mm} \mathrm{Hg}(4.8 \mathrm{kPa})$. Two days after intubation a pulmonary artery catheter was introduced through the right subclavian vein. After four days of artificial mechanical ventilation the patient developed severe hypotension and died. The peak airway pressure had been $55 \mathrm{~cm} \mathrm{H}_{2} \mathrm{O}$.

\section{Pathological findings}

At necropsy two cavitated infarcts were found in the posterior and lateral basal segments of the left lower lobe. The posterior lesion, which measured $2.5 \times 3.8$ $\mathrm{cm}$, was nearly entirely excavated; the other infarct surrounded a cavity $0.8 \mathrm{~cm}$ in diameter. The necrotic lung around each cavity was overgrown with Gram negative bacteria and rare acid fast bacilli; there was negligible infiltration with inflammatory cells. The visceral pleura was necrotic, but intact over each lesion. Many large, bland, thromboemboli occluded the main and lower lobe segmental pulmonary artery branches. Thromboemboli and non-cavitated infarcts were present in the right lung Other findings in the lungs included diffuse alveolar damage in the exudative phase and disseminated miliary tuberculosis. A recent thrombus, less organised than the pulmonary artery clots, had formed in the superior vena cava around the pulmonary artery catheter.

\section{CASE 3}

A 34 year old man was admitted to the burn unit with partial thickness burns over $40 \%$ of his body surface area and with injury from smoke inhalation resulting from a house fire. On the first hospital day he underwent endotracheal intubation. His wounds were surgically excised and debrided. Postoperatively his temperature rose to $39^{\circ} \mathrm{C}$ and treatment with nafcillin, tobramycin, and ticarcillin was instituted. The chest radiograph at that time showed bilateral diffuse nodular infiltrates. On the third hospital day a flow directed pulmonary artery catheter was inserted via the right subclavian vein. The initial pulmonary artery pressure was $45 / 24 \mathrm{~cm} \mathrm{H}_{2} \mathrm{O}(33 / 18 \mathrm{~mm} \mathrm{Hg})$ and the pulmonary capillary wedge pressure was $20 \mathrm{~cm} \mathrm{H}_{2} \mathrm{O}$ 
$(14 \mathrm{~mm} \mathrm{Hg})$. Over the following two days the pulmonary capillary wedge pressure decreased to $16 \mathrm{~cm}$ $\mathrm{H}_{2} \mathrm{O}(12 \mathrm{~mm} \mathrm{Hg})$, and the pulmonary artery catheter was replaced with a single lumen central venous catheter. Throughout the remainder of the course of his illness his temperature varied from $38.5^{\circ}$ to $40^{\circ} \mathrm{C}$. Sputum cultures yielded normal oral flora. Serial chest radiographs showed progressively increasing bilateral ill defined nodular densities. Institution of mechanical ventilation with fractional inspired oxygen concentrations of $0.40-0.50$ and positive end expiratory pressures of 7-17 $\mathrm{cm} \mathrm{H}_{2} \mathrm{O}$ resulted in arterial blood oxygen tensions of $80-90 \mathrm{~mm} \mathrm{Hg}(10.6-12.0 \mathrm{kPa})$. On the ninth hospital day further surgical debridement of infected eschars was attempted. During the operation the patient's $\mathrm{PaCO}_{2}$ increased abruptly to $80 \mathrm{~mm} \mathrm{Hg}$ $(10.6 \mathrm{kPa})$ and the $\mathrm{PaO}_{2}$ fell to $40 \mathrm{~mm} \mathrm{Hg}(5.3 \mathrm{kPa})$. The peak airway pressure was $62 \mathrm{~cm} \mathrm{H}_{2} \mathrm{O}$. Subsequently bradycardia and hypotension developed, followed by a cardiac arrest, and the patient died.

\section{Pathological findings}

At necropsy both lungs were non-crepitant and diffusely fibrotic. Multiple macroscopic and microscopic thromboemboli were present in segmental and subsegmental arteries bilaterally. In the right middle lobe there was a $2.2 \times 1.8 \mathrm{~cm}$ cavitated infarct. The pleura immediately overlying this lesion appeared viable, and within the infarct no microorganisms were demonstrable histologically. Non-infected organising thrombi were present in the superior vena cava and adherent to the tricuspid and pulmonary valves and to the right atrial endocardium.

\section{CASE 4}

A 58 year old woman with recently diagnosed mammary and gastric adenocarcinomas aspirated her gastric contents and subsequently developed respiratory insufficiency. Endotracheal intubation and mechanical ventilation with an $\mathrm{FiO}_{2}$ of 0.60 and a PEEP of 15 $\mathrm{cm} \mathrm{H}_{2} \mathrm{O}(1.5 \mathrm{kPa})$ was required to achieve $\mathrm{a}^{\mathrm{PaO}_{2}}$ of $65 \mathrm{~mm} \mathrm{Hg}(8.6 \mathrm{kPa})$. A chest radiograph showed bilateral patchy infiltrates. A flow directed pulmonary artery catheter was inserted and over the subsequent three weeks the catheter was replaced three times through the initial insertion site. Her hospital course was complicated by septicaemia with Gram negative bacteria and Candida albicans. Ten days before death chest tubes were placed in both pleural space for prophylactic purposes. Later a gas leak developed through the right chest tube, indicating a bronchopleural fistula. The peak airway pressures ranged from 38 to $42 \mathrm{~cm} \mathrm{H}_{2} \mathrm{O}$ (3.7 to $4.1 \mathrm{kPa}$ ). Cultures of the fluid drained from both chest tubes yielded mixed Gram negative bacillary organisms. Despite antibiotic treatment and intravenous administration of vaso- pressors, the patient developed refractory hypotension and acidosis and died.

\section{Pathological findings}

At necropsy both lungs were diffusely consolidated. In the right lower lobe there were two pleural based cavities in the posterior and lateral basal segments measuring $5 \mathrm{~cm}$ in diameter. Both cavities were surrounded by necrotic, inflamed lung tissue, and communicated with the pleural space through large visceral pleural defects. Bland, organising, focally calcified thromboemboli were found occluding segmental arteries at the apex at each cavity (fig 2 ) as well as other arteries in the upper and middle lobe. A recent, bland infarct $2 \mathrm{~cm}$ in diameter was present in the middle lobe. The lung parenchyma was diffusely fibrotic with multifocal acute bronchopneumonia, from which Klebsiella pneumoniae was cultured.

\section{CASE 5}

A 55 year old man was admitted to hospital with complaints of a non-productive cough and shortness of breath. A chest radiograph showed bilateral pulmonary infiltrates. A stained specimen of sputum showed a few polymorphonucear leucocytes but no bacteria. Treatment with penicillin, gentamycin, and frusemide was instituted. Two days later, because of deterioration in gas exchange, he underwent endotracheal intubation and artificial mechanical ventilation was instituted. A flow directed pulmonary artery cather was inserted via the right subclavian vein; the initial pulmonary capillary wedge pressure was $15 \mathrm{~cm} \mathrm{H}_{2} \mathrm{O}(11 \mathrm{~mm} \mathrm{Hg})$. His temperature was $40^{\circ} \mathrm{C}$. After two weeks an open biopsy of his right lung was performed. Histological examination of lung tissues showed advanced interstitial and intra-alveolar fibrosis. No microorganisms were identified. Scattered thromboemboli were observed, however, in the microvasculature. A presumptive diagnosis of nonbacterial pneumonia was made. The antibiotics he was having were discontinued and treatment with diuretics, corticosteroids, and erythromycin was instituted. There was a progressive deterioration throughout the remainder of his hospital stay. Mechanical ventilation with an inspired oxygen concentration of $0.50-0.75$ and a PEEP of $10-15 \mathrm{~cm} \mathrm{H}_{2} \mathrm{O}$ was required to achieve an arterial oxygen tension of $60 \mathrm{~mm} \mathrm{Hg}(8$ $\mathrm{kPa}$ ). Peak airway pressures ranged from 55 to $70 \mathrm{~cm}$ $\mathrm{H}_{2} \mathrm{O}$. One week later the patient suddenly experienced chest pain, which was followed by cardiopulmonary arrest and death.

\section{Pathological findings}

At necropsy the lungs were diffusely consolidated. A $5 \times 6.2 \mathrm{~cm}$ cavitated infarct, adjacent to necrotic visceral pleura, was found in the anterior segment of 


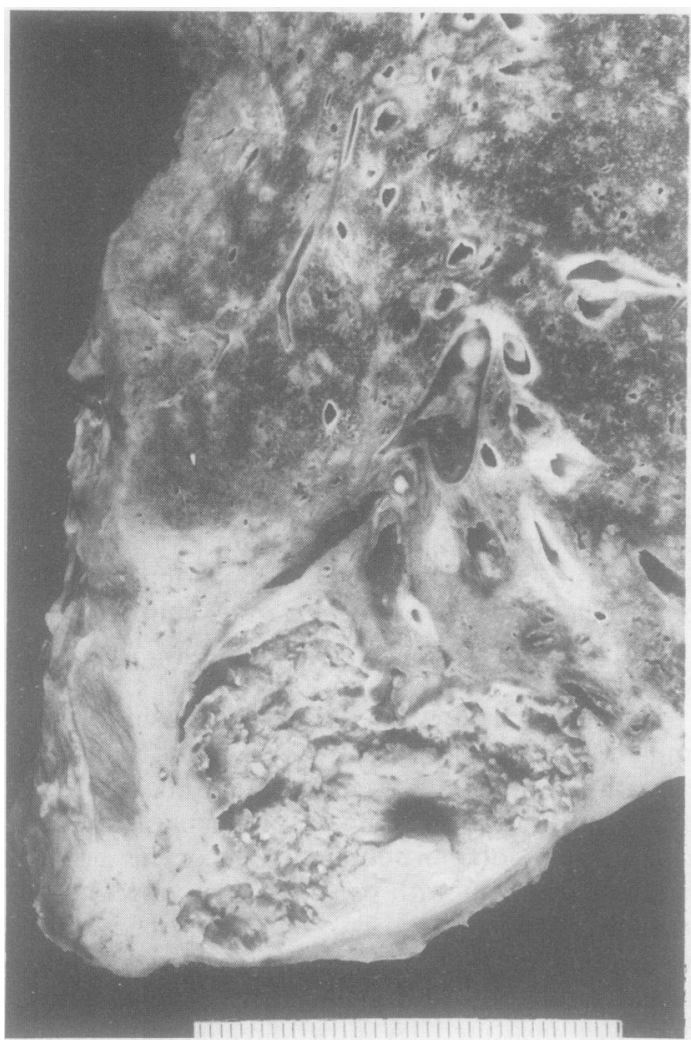

Fig 2 Patient 4: An abscess is present within the lower lobe infarct at the bottom of the photograph. Note a large occlusive thromboembolus in the artery at the apex of the lesion. The pleura bordering the cavity is necrotic. Pale areas above the infarct are foci of bronchopneumonia. (Scale in $\mathrm{mm}$.)

the left upper lobe. Focal disruption of the pleura was observed microscopically. A thromboembolus was seen in the segmental artery proximal to the lesion, and multiple other microthromboemboli were observed bilaterally. The wall of the cavity and the surrounding necrotic parenchyma were heavily colonised with bacteria and yeast.

\section{Discussion}

Bland pulmonary thromboembolism occurs commonly in hospital inpatients and is particularly prevalent in the critically ill. ${ }^{3}$ There were many factors predisposing to the development of thromboembolic disease in our patients. One potential source was superior vena cava thrombosis associated with the presence of an indwelling vascular catheter. All of our patients had flow directed pulmonary artery catheters inserted two to 21 days before death. In three cases catheter related thrombi were found in the superior vena cava, but in the other two the catheter path was not completely inspected. Recently Castele $e t$ al found central venous and right atrial thrombi at postmortem examination in 16 of 32 patients who were brought to necropsy with a pulmonary artery catheter in place. ${ }^{4}$ These findings indicate that, in addition to the iliofemoral veins, the superior vena cava and its tributaries may represent an important potential source of pulmonary emboli in critically ill patients. ${ }^{5}$

Lung cavitation following bland thromboembolism is unusual; the incidence is only $2.7-4.2 \%^{6-8}$ The development of bronchopleural fistula secondary to bland infarction is even more rare, only 25 such cases having been reported before $1977 .^{9}$ The relatively large number of cases of pulmonary infarction associated with cavitation and pneumothorax that we observed in a short time was therefore unexpected. We suggest that the adult respiratory distress syndrome in association vascular injury, pulmonary infection, and the raised alveolar pressures resulting from positive pressure mechanical ventilation may predispose to cavitation of infarcts and the formation of bronchopleural fistula after bland thromboembolism.

Extensive vascular abnormalities are commonly found in patients with adult respiratory distress syndrome. ${ }^{10}$ Widespread filling defects in small pulmonary arteries have been demonstrated radiographically by balloon occlusion angiography ${ }^{11}$ and histological evidence of microemboli can be found in the lungs of virtually all patients who have died of adult respiratory distress syndrome. ${ }^{12}$ These abnormalities have been attributed to vascular endothelial cell injury and to increased pulmonary sequestration of platelets. ${ }^{13}$ Distortion of blood vessels due to pulmonary firosis and compression caused by interstitial oedema may lead to local impairment in blood flow. ${ }^{1415}$ These abnormalities of pulmonary perfusion in adult respiratory distress syndrome are preferentially localised to peripheral subpleural regions. ${ }^{16}$ Since these regions tend to have less collateral blood flow from other pulmonary arteries or the bronchial circulation (or both), there is a greater susceptibility to tissue necrosis, particularly when pulmonary perfusion is further compromised by thromboembolic obstruction of larger arteries ( $>1 \mathrm{~mm}$ diameter). ${ }^{16}$

Tissue necrosis and cavitation are common after septic thromboembolism. Because of the absence of bacteria within either the pulmonary emboli or the extrapulmonary sites of phlebothrombosis we believe that septic embolisation was unlikely in our patients Nevertheless, pre-existing or secondary infection in the areas of lung infarction did appear to contribute to parenchymal necrosis. In two instances histological findings suggested that the infarcts had become secondarily infected. In another two cases pulmonary thromboemboli appeared to occlude vessels in areas 
of pre-existing pneumonia. The propensity of devitalised tissue to become infected and the accelerated growth of microorganisms in poorly perfused tissue ${ }^{1617}$ seem to have contributed to the prominent parenchymal necrosis observed in the subpleural areas of infarction.

In the absence of pulmonary disease barotrauma is unusual, with peak airway pressures of less than 60-80 $\mathrm{cm} \mathrm{H}_{2} \mathrm{O} .{ }^{18}$ In the presence of underlying lung damage, however, pleural disruption may be associated with much lower airway pressures. ${ }^{19}$ The role of high airway pressures in the pathogenesis of bronchopleural fistula in association with cavitary infarction has previously been noted by Mundth $e t$ $a l^{20}$ who reported three cases of severe cardiovascular disease and bland infarction with bronchopleural fistulas following mechanical ventilation. The patients we studied were all mechanically ventilated and positive end expiratory pressures of $5-18 \mathrm{~cm}$ $\mathrm{H}_{2} \mathrm{O}$ were in use for four to 29 days before death. Peak airway pressures ranged from 38 to $70 \mathrm{~cm} \mathrm{H}_{2} \mathrm{O}$. There was clinical evidence of pneumothorax in two cases and in three cases disruption of the pleura surrounding cavitated infarcts was noted histologically. These observations suggest that increased airway pressure may predispose to barotrauma in settings where pulmonary thromboembolism is most likely to lead to tissue necrosis.

Despite the high prevalence, thromboembolism is often clinically undetected in patients with diffuse lung injury. ${ }^{20}$ This report has shown that careful examination of formalin inflated lungs identifies an unexpectedly high number of cavitary infarcts associated with bland thromboembolism. We suggest that pulmonary infarction should be seriously considered in the differential diagnosis of cavitary lung lesions or of bronchopleural fistula in patients with adult respiratory distress syndrome. Although the most appropriate means of managing the diffuse vascular lesions of adult respiratory distress syndrome is unresolved, ${ }^{3}$ rigorous treatment of extrapulmonary sites of thrombosis and the prevention of superior vena caval thrombosis associated with prolonged central venous catheterisation might lead to the prevention of additional vascular injury. In this setting the development of bronchopleural fistula during mechanical ventilation should be anticipated and attempts should be made to reduce high airway pressures.

\section{References}

1 Fraser RG, Pare JAP. Diagnosis of diseases of the chest. Philadelphia: Saunders, 1978:1140.
2 Freiman DG, Suyemoto T, Wellster S. Frequency of pulmonary thromboembolism in man. $N$ Engl $J$ Med 1965;272:1278-81.

3 Moser KM. Pulmonary embolism. Am Rev Respir Dis 1977;115:829-52.

4 Castele RJ, Connors AF, Farhat N, Tomashefski JF jun. Complications of right heart catheterization [abstract]. Am Rev Respir Dis 1983;127, suppl: 89.

5 Goodman DJ, Rider AK, Billingham ME, Schroeder TS. Thromboembolic complications with the indwelling balloon-tipped pulmonary artery catheter. $N$ Engl $J$ Med 1974;291:777.

6 Levin L, Kernohan JW, Moersch HJ. Pulmonary abscess secondary to bland pulmonary infarction. Dis Chest 1948;14:218-32.

7 Grieco MH, Ryan SF. Aseptic cavitary pulmonary infarction. Am J Med 1968;45:811-6.

8 Coke LR, Dunde JC. Cavitation in bland infarcts of the lung. Can Med Ass J 1955;72:907.

9 Hall FM, Salzman EW, Ellis I, Kurland GS. Pneumothorax complicating aseptic cavitating pulmonary infarction. Chest 1977;72:232-4.

10 Snow RL, Davies P, Pontoppidan H, Zapol WM, Reid L. Pulmonary vascular remodeling in adult respiratory distress syndrome. Am Rev Respir Dis 1982;126:887-92.

11 Greene R, Zapol WM, Snider MT, et al. Early bedside detection of pulmonary vascular occlusion during acute respiratory failure. Am Rev Respir Dis 1981;124:593-601.

12 Tomashefski JF jun, Davies P, Boggis C, Greene R, Zapol WM, Reid L. Pulmonary vascular lesions of the adult respiratory distress syndrome. Am J Pathol 1983;112:112-26.

13 Schneider RC, Zapol WM, Carvalho AC. Platelet consumption and sequestration in severe acute respiratory failure. Am Rev Respir Dis 1980;122:445-51.

14 Zapol WM, Kobayashi K, Snider MT, Greene R, Laver $M B$. Vascular obstruction causes pulmonary hypertension in severe acute respiratory failure. Chest 1977;71, suppl:3065-75.

15 Carvalho A, Greene R, Boggis C, Quinn D, Ried L, Zapol WM. Intravascular coagulation with fibrinolysis in patients with acute respiratory failure and angiographic pulmonary vascular occlusion [abstract]. Am Rev Respir Dis 1982;125, suppl:93.

16 Jones R, Zapol WM, Tomashefski JF jun, Kirton OC, Kobayashi K, Reid L. Pulmonary vascular pathology in the adult respiratory distress syndrome: human and experimental studies. In: Zapol WM, Falke RK, eds. Acute respiratory failure. New York: Marcel Dekker (in press).

17 Harvey TC, Sabiston DC. Empyema as a complication of bland pulmonary infarction. Ann Intern Med 1954; 40:285.

18 Steir M, Ching N, Roberts EB, Nealon TF. Pneumothorax complicating continuous ventilatory support. $J$ Thorac Cardiovasc Surg 1974;67:17-23.

19 Johnston RF, Dovarnsky TH. Pleural diseases. In: Fishman AP, ed. Pulmonary diseases and disorders. New York: McGraw-Hill, 1980:1374.

20 Mundth ED, Foley FD, Austen WG. Pneumothorax as a complication of pulmonary infarction in patients on positive pressure respiratory assistance. $J$ Thorac Cardiovasc Surg 1965;50:555-60. 